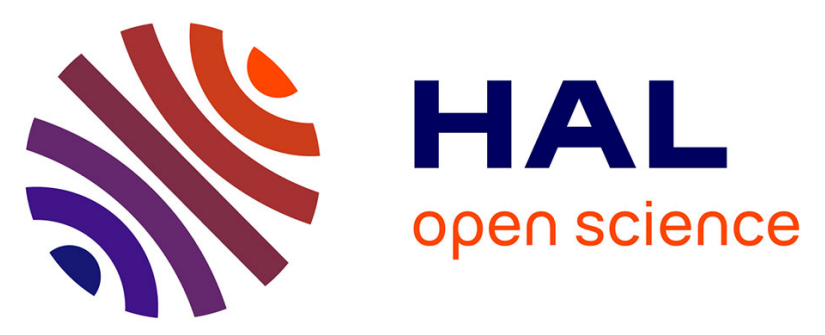

\title{
Results On Australia And New Zealand Second Generation SBAS And PPP Augmentation System
}

\author{
Julian Barrios Lerma, José Caro, Guillermo Fernández, José Gabriel \\ Pericacho, Víctor Manuel Esteban, Miguel Angel Fernández Vidou, Fernando \\ Bravo Llano, Alessandra Calabrese, Armais Diaz Chavez, Jesus David Calle, \\ et al.
}

\section{To cite this version:}

Julian Barrios Lerma, José Caro, Guillermo Fernández, José Gabriel Pericacho, Víctor Manuel Esteban, et al.. Results On Australia And New Zealand Second Generation SBAS And PPP Augmentation System. 5th International Technical Symposium on Navigation and Timing (ITSNT 2018), Nov 2018, Toulouse, France. 10.31701/itsnt2018.05 . hal-01942244

\section{HAL Id: hal-01942244 \\ https://hal-enac.archives-ouvertes.fr/hal-01942244}

Submitted on 4 Feb 2019

HAL is a multi-disciplinary open access archive for the deposit and dissemination of scientific research documents, whether they are published or not. The documents may come from teaching and research institutions in France or abroad, or from public or private research centers.
L'archive ouverte pluridisciplinaire HAL, est destinée au dépôt et à la diffusion de documents scientifiques de niveau recherche, publiés ou non, émanant des établissements d'enseignement et de recherche français ou étrangers, des laboratoires publics ou privés. 


\title{
Results on Australia and New Zealand Second Generation SBAS and PPP Augmentation System
}

\author{
Julián Barrios $^{(1)}$, Jose Caro ${ }^{(1)}$, Guillermo Fernández ${ }^{(1)}$, Jose Gabriel Pericacho ${ }^{(1)}$, Victor Manuel Esteban ${ }^{(1)}$, Miguel Angel \\ Fernández $^{(1)}$, Fernando Bravo ${ }^{(1)}$, Alessandra Calabrese ${ }^{(1)}$, Armais Diaz Chavez $^{(1)}$, Jesus David Calle ${ }^{(1)}$, Enrique Carbonell ${ }^{(1)}$, \\ Miguel M. Romay ${ }^{(1)}$, Irma Rodriguez ${ }^{(1)}$, Maria Dolores Laínez ${ }^{(1)}$, Robert, Jackson ${ }^{(2)}$, Patrick E. Reddan ${ }^{(3)}$, Deane Bunce ${ }^{(3)}$, \\ Claudio Soddu ${ }^{(4)}$ \\ ${ }^{(1)} G M V,{ }^{(2)} L M,{ }^{(3)}$ Zeta Associates, ${ }^{(4)}$ Inmarsat
}

Email: jbarrios@gmv.com

\begin{abstract}
During 2017 and 2018 a second generation satellite positioning augmentation system is being demonstrated in Australia and New Zealand. This system provides Satellite Based Augmentation (SBAS) and Real Time Precise Point Positioning (PPP) capabilities through the SBAS L1 and L5 signals broadcasted from the Inmarsat 4F1 geostationary satellite.
\end{abstract}

The Australia and New Zealand SBAS and PPP testbed is promoted by Geoscience Australia (GA), Land Information New Zealand (LINZ), and the Australia and New Zealand Cooperative Research Centre for Spatial Information (CRCSI). The system is developed in collaboration with industry partners, including Lockheed Martin, Inmarsat and GMV.

The services and signals broadcast during the testbed consist of:

- $\quad$ SBAS L1 legacy service available for GPS L1 singlefrequency users over Australia and New Zealand.

- $\quad$ SBAS DMFC L5 service available for GPS L1/L2 + GAL E1/E5a dual-frequency users over the Inmarsat 4F1 footprint.

- $\quad$ PPP corrections through SBAS L1 message, targeting GPS L1/L2 dual-frequency users

- $\quad$ PPP corrections through SBAS L5 message, targeting GPS L1/L2 + GAL E1/E5a dual-frequency users.

The transmissions of SBAS signals started in May 2017, while the transmission of the PPP services started in October 2017.

The main goal of this paper is to provide, from the point of view of the system developers, an update on the testbed service definition, infrastructure status and performances achieved during the 2017-2018 system operation.

\section{INTRODUCTION}

Early 2017, the Australian and New Zealand governments announced the initiation of the 2nd Generation SBAS testbed including the demonstration of applications in transport and other industry sectors. GMV together with Lockheed Martin Space Systems Company and Inmarsat launched a two year collaborative project with Geoscience Australia (GA), the Collaborative Research Centre for Spatial Information (CRCSI) and Land Information New Zealand (LINZ) for the deployment of a satellite positioning augmentation testbed system.

The results of the planned demonstrations will provide substantive proof of how this technology can benefit safety, productivity, efficiency and innovation in Australian and New Zealand industrial and research sectors.

The testbed is allowing the evaluation of a wide range of GNSS augmentation technologies including integrity and high-precision techniques. The proposed technological solution combine the SBAS service with PPP technologies. This allows the service to satisfy aviation and other user communities with a common infrastructure.

The testbed is continuously broadcasting 4 services.

- $\quad$ SBAS L1 Legacy service since May 2017

- $\quad$ SBAS L5 DFMC service since Oct 2017

- $\quad$ RT-PPP through SBAS L1 since Oct 2017

- $\quad$ RT-PPP through SBAS L5 since Oct 2017

The testbed will be transmitting its services at least until February 2019

\section{TESTBED SERVICES DEFINITION}

\subsection{GEO broadcasted signals}

The Australian and New Zealand test bed is broadcasting two different signals through the Inmarsat 4F1 satellite:

- $\quad$ SBAS L1 signal at $1575.42 \mathrm{MHz}$

- $\quad$ SBAS L5 signal at $1176.45 \mathrm{MHz}$

The data broadcasted through each one of this channels support both an SBAS and PPP signal as described in the following sections. 


\subsection{SBAS L1 Legacy}

SBAS L1 legacy service is broadcasted using PRN 122 in accordance with RTCA/DO-229D [1] (as EGNOS and WAAS). The service is declared for test purposes only (don't use for safety applications) and therefore is broadcasting MT 0 message every 6 seconds.

The SBAS L1 message broadcast both corrections and integrity information for GPS satellite ephemeris and a regional ionosphere. In the scope of the testbed the region is defined to cover the Australia and New Zealand territories as described in the next figure:

Figure 1 - SBAS L1 Service Area

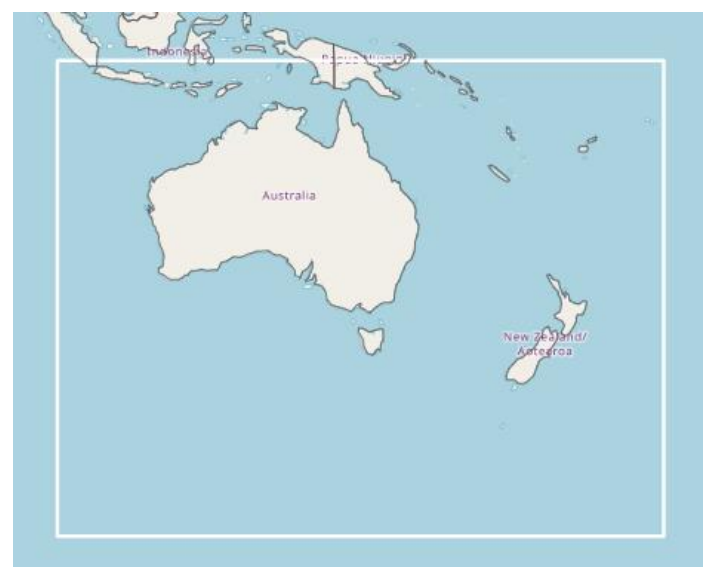

This service is accessible to receivers available in the market with SBAS-enabled mode. There is a wide variety of receivers supporting this mode thanks to EGNOS and WAAS implantation in the European and North American coverage area.

SBAS L1 augmentation can support user accuracies in the order of the 0.5 meters RMS and LPV-200 navigation performances.

\subsection{SBAS L5 DFMC}

The Dual-frequency and Multi-constellation (DFMC) is the new generation of the SBAS services. It targets dualfrequency receivers are able to remove the major part of the ionospheric error through the use of the iono-free combination. Since the augmentation system does not need to provide corrections and integrity to the ionosphere, an important part of the channel bandwidth is free and can be used to provide corrections and integrity to additional constellations. Also, because the service is not constrained to the region in which the ionosphere is estimated, it can be used in the whole foot-print of the GEO. The availability of a greater number of satellites shall be translated in the capability to provide better navigation performances including CAT-I and accuracies in the order of 0.5 meters RMS.

The Australian SBAS DFMC L5 service is implemented in accordance with WG62 GAL GPS SBAS MOPS v0.3.8_10 draft [2], which is was latest draft version available at the beginning of the testbed broadcast.

The testbed signal is providing corrections for GPS L1/L2 + GAL E1/E5a iono-free combination and the coverage area corresponds to the foot-print of the PRN 122 GEO.
Since the testbed is transmitting a very recently defined message no commercial SBAS L5 receivers was available. In order to allow the access to the services the consortium team has developed its prototype equipment's allowing to run the user position algorithms.

Figure 2 - PRN 122 footprint

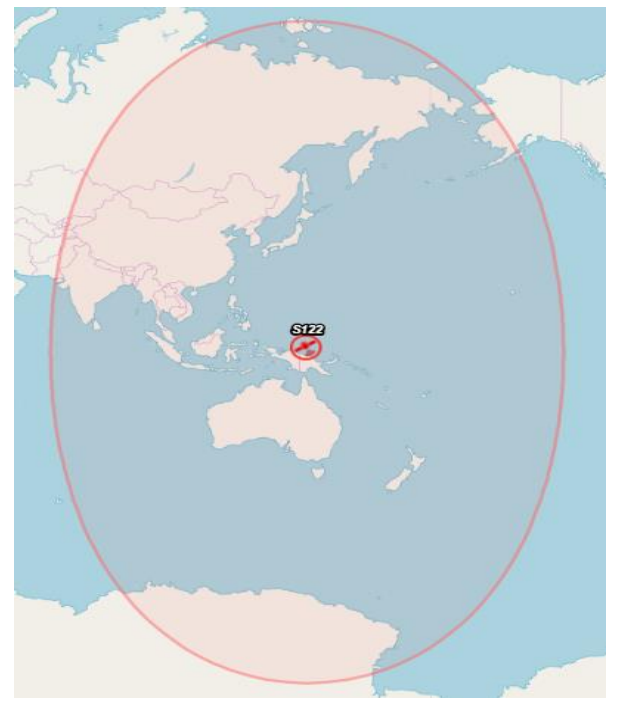

\section{$2.4 \quad$ RT-PPP through SBAS}

The provision of the RT-PPP Service depends on the service provider capability to broadcast real-time precise corrections for satellite clocks and orbits in the order of a few centimetres of error. When this information is available, PPP user receivers can achieve accuracies of 10 $\mathrm{cm}$.

The traditional means for the transmission of these corrections includes internet streams or proprietary satellite link connections.

The approach followed in the testbed solution is to use the SBAS messages to broadcast the PPP corrections. In the case of the SBAS L1 service the resolution of the message correction too big in order to support the transmission of high-precision corrections.

To avoid this limitation, the testbed solution is to use the SBAS spare bits present in the SBAS message to include additional information with a higher resolution. This is compatible with the SBAS service, as the SBAS receivers following the standard are instructed to ignore this bits. However PPP dedicated receivers can use this information to access the high accuracy data.

The PPP information included in the SBAS messages is accessible to the dedicated receivers developed as part of the Australia and New Zealand testbed context.

The PPP corrections transmitted within the SBAS L1 provides corrections for GPS L1/L2 frequencies while the PPP corrections transmitted through the SBAS L5 signal provide corrections for GPS L1/L2 + GAL E1/E5a frequencies. Both services are available in the whole GEO footprint. 


\subsection{Overall view}

The Australia and New Zealand testbed includes the necessary infrastructure for the generation of SBAS L1 and SBAS L5 DFMC augmentation signals broadcasting both SBAS and PPP corrections. The basis of an SBAS augmentation system consist on the use of the observations acquired by a set of reference stations whose position is known at $\mathrm{cm}$ level to estimate and compute the errors and distortion produced at common elements of the GNSS transmission path. The computed information is transmitted to the user through the GEO signal. This allows the SBAS user to remove the estimated errors of its computations and to assess the error of its own position determination leading to the SBAS integrity concept.

The list of elements included in the system architecture, as well as its organization is depicted in Figure 3. The architecture is comprised of four distinct segments which are briefly described in the following sections.

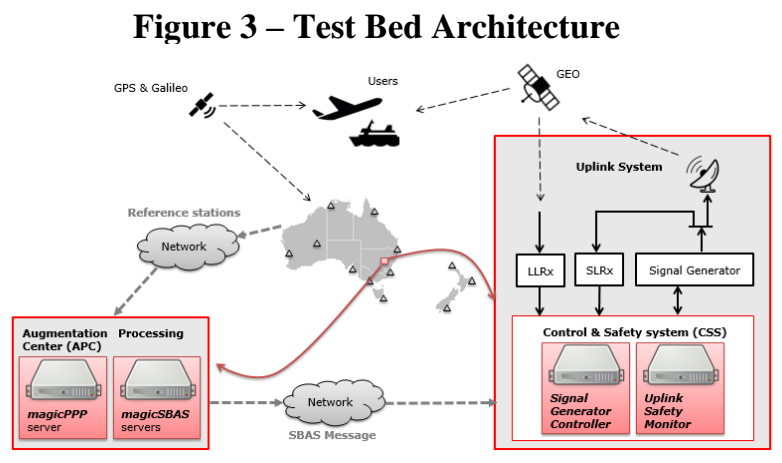

\subsection{Space Segment (SS)}

In addition to the GPS and Galileo constellation, the testbed space segment consists of the Inmarsat-4F1 GEO satellite used for broadcast of the SBAS signals.

\subsection{Ground Segment: Reference Stations}

A set of reference stations with known calibrated locations is needed in order to support the computation of the SBAS messages. The definition of this network of stations needs to follow different criteria when considering the SBAS L1 and SBAS L5 cases.

On one hand, the SBAS L1 producing ionospheric corrections requires a high density receiver's network located in the service area in order to acquire a sufficient number of measurements to support the ionosphere monitoring and determination. On the other hand, the SBAS L5 producing dual-frequency corrections is free from the ionospheric monitoring requirement and requires a much more sparse reference stations network to monitor satellites orbits and clocks. In the Australia and New Zealand testbed solution, GMV has chosen to select a world-wide reference station network. The following figures depicts the reference network configured for the provision of the SBAS L1 and SBAS L5 Services.
Figure 4 - SBAS L1 Regional Network

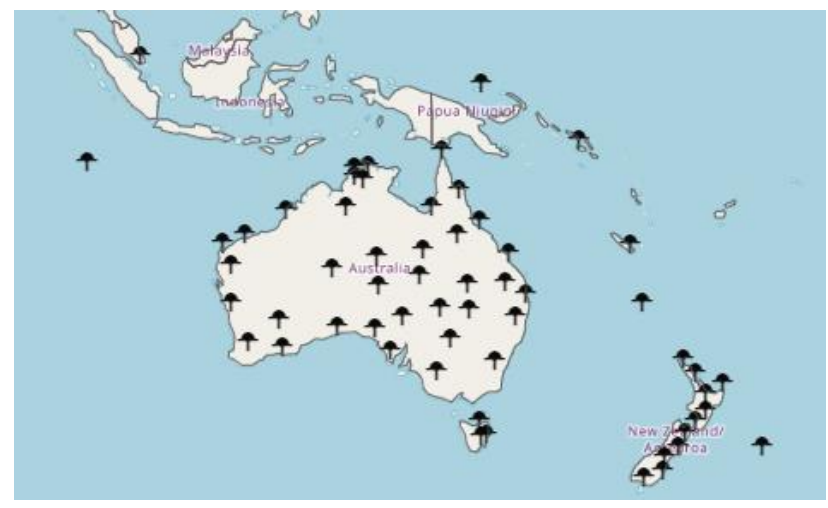

Figure 5 - SBAS L5 WW Network

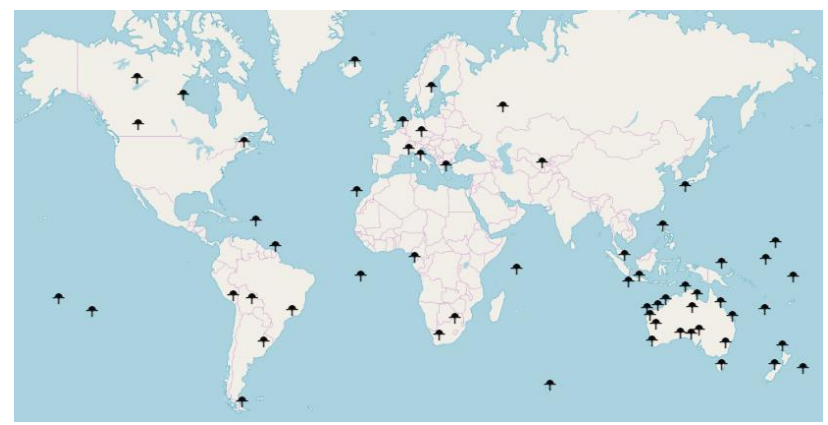

Unlike the architecture of operational SBAS System such as WAAS or EGNOS, the Australia and New Zealand testbed is using a diversified set of general purpose receivers whose data is made available through internet connection. This introduce some constraints into the reliability of the data which mainly depends on the receivers own operation (which is independent of SBAS mission) and the internet connection.

Under these conditions, the situation in which a receiver stops to provide data to the testbed in an unplanned way is not a rare event. In order to mitigate this situation and also to provide a greater robustness to the system performance, the number of stations configured is higher than what would be necessary in an operational SBAS system with dedicated equipment, sites and communication link.

Also, the facts that the receivers are diversified makes important to tune and adapt the estimation algorithms to a very flexible range of behavior, in particular those corresponding to the receiver clocks synchronization.

\subsection{Ground Segment: Uralla Station Center}

The elements in charge of computing and generating the SBAS message are located at the Uralla station in New South Wales. The Uralla station is operated by Lockheed Martin personnel with the support of Zeta, Inmarsat and GMV teams.

The station includes the Augmentation Processing Centre which processes the measures received from the reference stations computes the PPP and SBAS corrections and builds the SBAS message to be transmitted.

International Technical Symposium on Navigation and Timing (ITSNT) 2018 
This message is transmitted to the Uplink infrastructure, which is charge of linking with the GEO so that the message can be broadcast. The APC is operated by Geoscience Australia with GMV support.

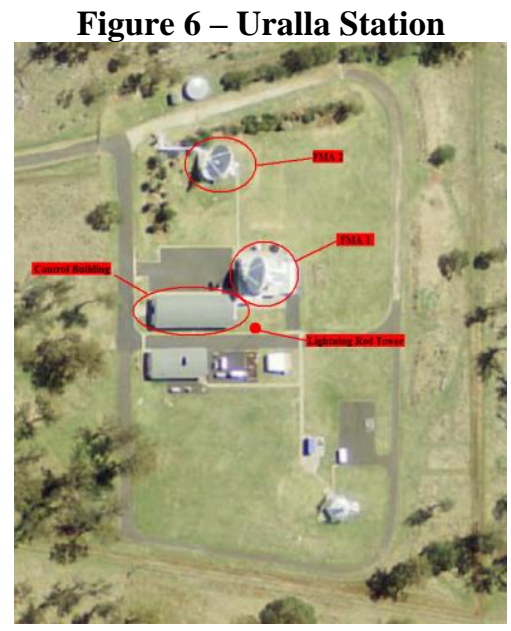

\subsection{Ground Segment: Augmentation Processing}

The measurements acquired by the stations are gathered and then processed to compute the SBAS and PPP corrections. GMV's products magicSBAS [3] and magicODTS [4] are deployed in Uralla, NSW, for that purpose.

- magicSBAS is a state-of-the-art, multi-constellation, operational SBAS infrastructure developed by GMV to offer SBAS regional differential corrections and non-safety critical integrity augmentation including $\mathrm{SV}$ and ionosphere corrections and integrity.

- $\quad$ magicODTS is a state-of-the-art orbit determination and time synchronization software that computes and estimates the GNSS satellite precise clock and orbits to a level of accuracy capable of sustaining PPP techniques.

\subsection{Ground Segment: Uplink Infrastructure}

Both the SBAS L1 and L5 signals are generated by means of the L1/L5 SBAS Signal Generator (SIGGEN) made available by Lockheed Martin and adjusted for the testbed by Zeta Associates. This equipment receives a binary SBAS message from magicSBAS and transforms this input into the electromagnetic signal to be uplinked to the GEO satellite. Additional elements are included in order to control and monitor the signal generator performance and to achieve a continuous transmission of the service. The overall Uplink infrastructure is composed of the following elements.

- Signal Generator (SIGGEN): component generating the electromagnetic signal that is transmitted to the GEO satellite for broadcasting to the users. The SIGGEN constructs the final SBAS message from the internal carrier wave and PRN codes plus the SBAS message proposed by magicSBAS.
- Signal Generator Controller (SGC): It is GMV's component providing the commanding for SIGGEN execution and monitoring the resultant outputs. Among its tasks, the SGC initializes the SIGGEN to the definition of the signal to be augmented (SBAS L1 and SBAS L5) and through the operation it commands the SIGGEN steering for the carrier frequency to compensate for Doppler effects on the signal uplink and downlink. SGC is also used as a hub for the communication between the different elements in the infrastructure.

- Uplink Safety Monitor (USM): It is the GMV's component element assessing the compatibility of the message with other systems before and after it is broadcast by the GEO. It includes checks over the contents of SBAS signal assuring it safety (among others it checks that SBAS L1 signal includes the MT_0 message at least once every 6 seconds, and that the Service Provider ID is the one assigned).

- FMA Antenna and its related infrastructure connects the station with the GEO and allows the final uplink of the signal that the Inmarsat $4 \mathrm{~F} 1$ satellite transponder converts and broadcast over the coverage area.

Figure 7 - Uplink Safety Monitor

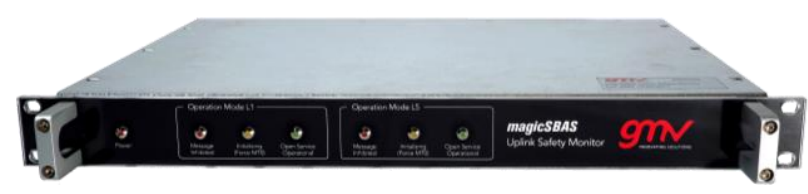

\subsection{Ground Segment: Support Segment}

The testbed includes a subsystem for the operation and maintenance of the SBAS testbed system. System performance for all Services are continuously monitored using GMV's magicGNSS Web Monitor, a web tool based on GNSS Monitoring Tools at System and User levels, and PPP Monitoring Tool for the Real Time PPP service. This monitoring tool, operated by GMV, is installed at GMV facilities and is accessible to the authorized users via an internet web server. It provides both real time monitoring of the system status and postprocessing of the services performances. 
Figure 8 - View of Testbed Operator Dashboard
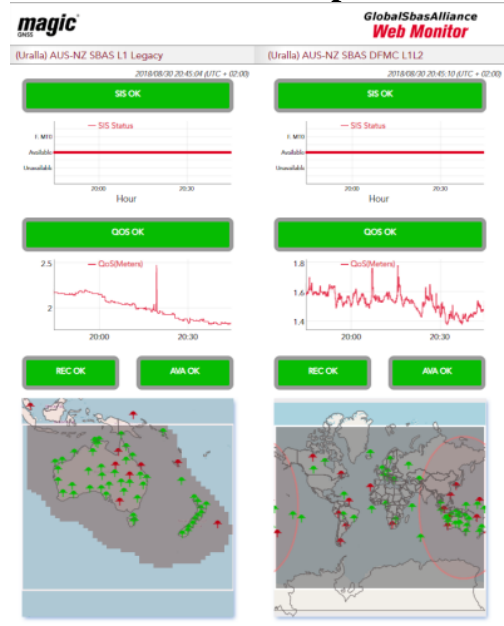

\subsection{User Segment}

To access to SBAS L1 Legacy service, users need to be equipped with a GPS+SBAS L1 C/A single-frequency receiver able to operate in non-safety critical mode. The SBAS L1 ICD is addressed to single-frequency users and, as a consequence, the Service transmits regional ionospheric corrections. There are several receivers in the market already including SBAS capabilities (sometimes called WAAS enabled). These receivers use the SBAS corrections in order to improve user position accuracy and are common in sectors such as maritime navigation and precision farming. In addition, the SBAS L1 services have been tested in aeronautic-like conditions with receivers supporting the processing of Non-SoL (MT0) signals.

In the case of the SBAS L5 DFMC Service, the users should be equipped with a multi-frequency and multiconstellation receiver capable of processing GPS L1 C/A and L5, Galileo E1 and E5a; as well as GEO L5 signals. The Service broadcast is based on the DFMC SBAS L5 ICD from March 2017, so COTS receivers might not be available. In order to mitigate this situation, GMV is proving to the trails coordinators two alternative receiver solutions to the testbed project.

In the first solution, the SBAS signals can be acquired through GMV's software receiver $\boldsymbol{S R} \boldsymbol{X}-10$ [5] In this solution, the SRX-10 can be used to acquire and decode the SBAS L1 or SBAS L5 broadcast messages and provide the information to other GMV analysis tools such as magicGEMINI [7] for SBAS, and magicAPK [6] for PPP.

On its second solution GMV has developed its own SBAS and PPP user terminal.

\section{Figure 9 - magicGNSS User Terminal}

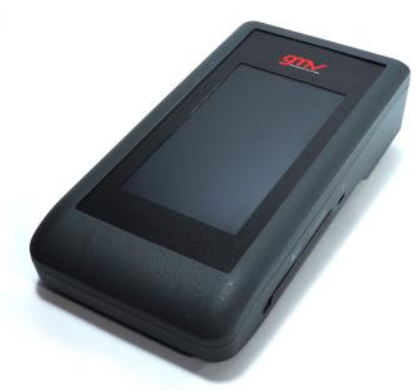

The main advantage of this device with regards to the SRX-10 solution is that it is a more compact and portable equipment. Its form factor is $110 \times 47 \times 39 \mathrm{~mm}$ with an approximate weight of $500 \mathrm{gr}$. It is designed to work as a fully standalone device, meaning that it is able to provide SBAS and PPP solutions without any external means independent of the GNSS and GEO constellation visibility.

\section{TESTBED SIGNAL PERFORMANCES}

The testbed activities have been carried out with a single SBAS chain with only one GEO and one Uplink Station. Obviously, this means that the system infrastructure can only accommodate elements maintenance and incidences with service shortages. However, in terms of the testbed mission and purpose this is an acceptable condition which allows to deploy the system under simplified condition that are logic in a testing and evaluation platform. Nevertheless, the evaluation of the percentage of the time that the signal has been transmitted is a valuable metric when considering the testbed performances.

At Uralla station, the Long Loop Receiver (LLRx) is in charge of tracking the SBAS L1 and SBAS L5 signals as broadcasted by the GEO through an OMNI Antenna located at the roof of the station.

The receiver plays a role in the process of SIGGEN generator controlling (particularly code and phase steering, CCC control and Doppler adjustment). The information tracked by this receiver has been used to build a statistic of the signal availability during 2018 .

Figure 10 - SIS Availability L1 (blue) and L5 (red)

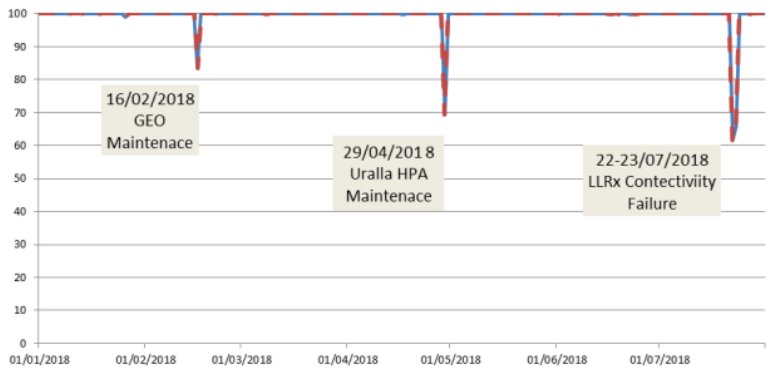


It can be observed how the availability is close to the $100 \%$ but for three events that caused the interruption of the signal transmission, related with maintenance operations and a station equipment failure.

When the availability plot is zoomed additional maintenance elements appear. They correspond to planned upgrades into the SGC software.

Figure 11 - Over $97.5 \%$ plot. L1 (blue) and L5 (red)

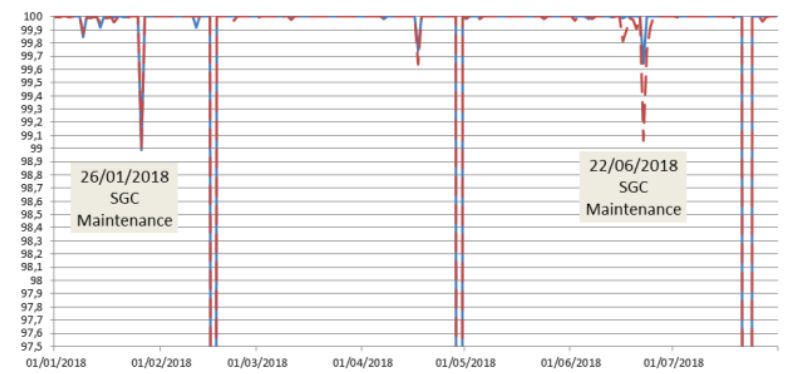

If the five identified major outages are discarded, it can be seen how the availability during 2018 is above the $99.99 \%$ for both signals. Table 1 and Table 2 provides the monthly availability as measured from the Long Loop Receiver, along with the availability after discarding the events.

Table 1 - 2018 Monthly availability in L1

\begin{tabular}{|c|c|c|}
\hline Month & L1 (\%) & $\begin{array}{c}\text { Filtered L1 } \\
(\%)\end{array}$ \\
\hline January & 99.959 & 99.992 \\
\hline February & 99.362 & 99.997 \\
\hline March & 100.000 & 100.000 \\
\hline April & 98.790 & 99.991 \\
\hline May & 100.000 & 100.000 \\
\hline June & 99.987 & 99.999 \\
\hline July & 97.133 & 100.000 \\
\hline
\end{tabular}

Table 2-2018 Monthly availability in L5

\begin{tabular}{|c|c|c|}
\hline Month & $\begin{array}{c}\text { L5 } \\
(\%)\end{array}$ & $\begin{array}{c}\text { Filtered L5 } \\
(\%)\end{array}$ \\
\hline January & 99.959 & 99.991 \\
\hline February & 99.359 & 99.998 \\
\hline March & 99.998 & 99.998 \\
\hline April & 98.779 & 99.987 \\
\hline May & 99.999 & 99.999 \\
\hline June & 99.942 & 99.972 \\
\hline July & 97.125 & 99.998 \\
\hline
\end{tabular}

The obtained outputs have an average number of data gaps of six messages per day. This is compatible with the expected performances of the LLRx receiver and are considered an artefact of the evaluation methodology (rather that a true discontinuity in the signal).

\section{STATIONS SBAS PERFORMANCES}

\subsection{Analysis Methodology}

AUSCORS maintains a FTP repository where $1 \mathrm{~Hz}$ RINEX files from the network stations are archived. This data has been used to perform a daily monitoring of the SBAS L1 and SBAS L5 performances by running user navigation algorithms over this data. The process is as follows:

1. Observation RINEX files are downloaded from AUSCORS FTP.

2. Navigation RINEX files are downloaded from AUSCROS FTP

3. SBAS message for L1 and L5 are downloaded from testbed Archive.

4. magicGEMINI [7] is used to evaluate the performances in two modes: GPS only and GPS+SBAS. Accuracy is measured as the error against the receiver calibrated position.

5. Outputs are processed to build historic data results. Days with observation RINEX availability lower than $80 \%$ are ignored in the analysis.

magicGEMINI is the GMV tool implementing the navigation user algorithm for SBAS L1 and SBAS L5 services. The analysis performed in the experimentation campaign is done by running the SBAS aeronautical solution. Only GPS stations are considered in the analysis.

\subsection{SBAS L1 Performances}

The following plots show the accuracy results for WARA station through 2018. Red lines represent the GPS only results, while green lines represent the GPS+SBAS solution. Average and P95 are included in the graphic.

\section{Figure 12 - WARA Horizontal Accuracy SF}

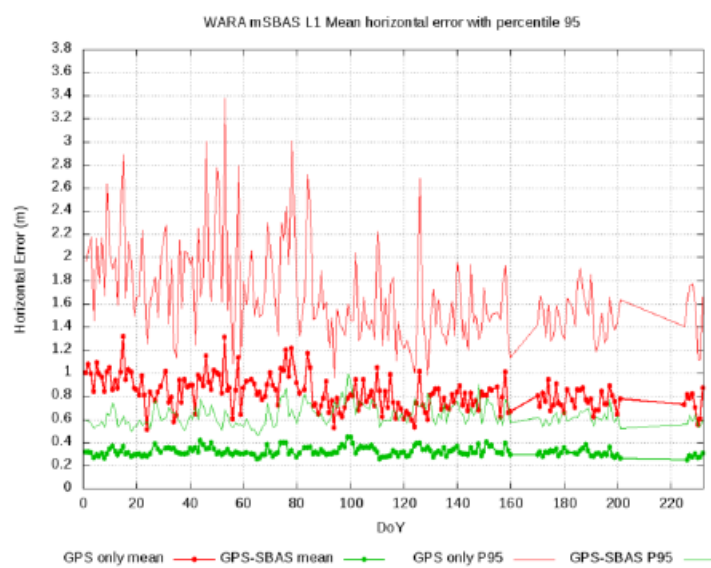


Figure 13 - WARA Vertical Accuracy SF

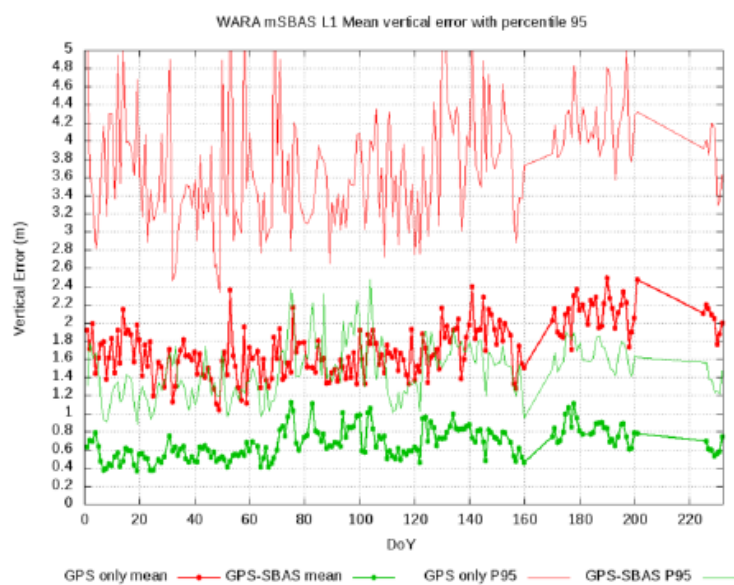

The obtained results show how the SBAS augmentation systematically improves the accuracy of the solution. The average accuracy of the SBAS L1 solution is around 0.5 meters. The P95 metrics are critically improved both in the Vertical and Horizontal solution. Improvements in the order of 1-2 meters are obtained for the vertical position.

The following diagram present the different clustering of the SBAS (green) and non SBAS (red) solution.

\section{Figure 14 - WARA Daily Mean Errors SF}

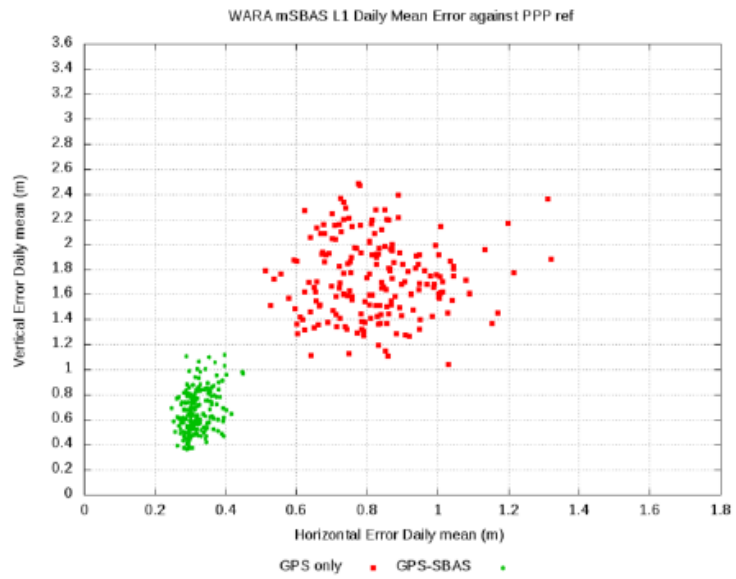

The following plot displays the vertical protection level average and P95 in comparison with the alert limits. The results indicate that the system solution is compatible with LPV-200 performances:
Figure 15 - SBAS L1 Vertical Protection Level

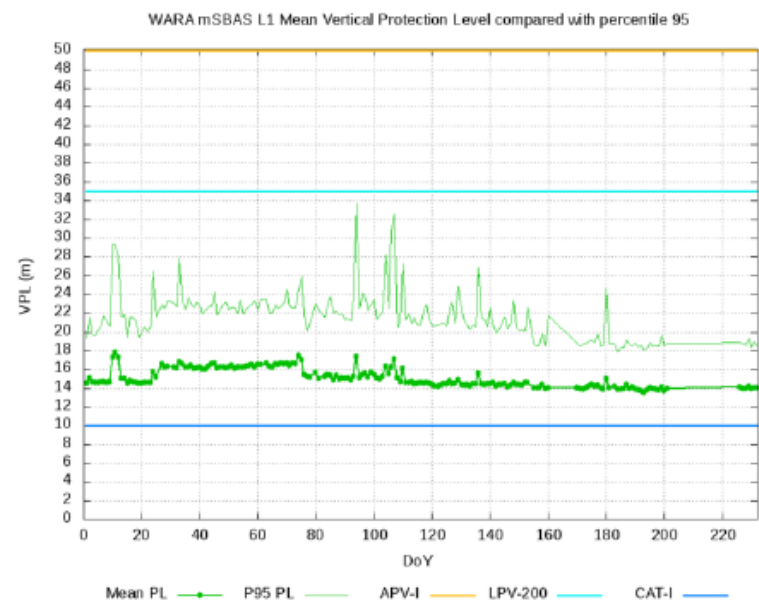

Finally, these results are reproduced when comparing the results in different stations. The following figures plots the change on the P95 vertical accuracy from the GPS only solution to the GPS+SBAS solution.

\section{Figure 16 - Vertical P95 SF (non SBAS)}

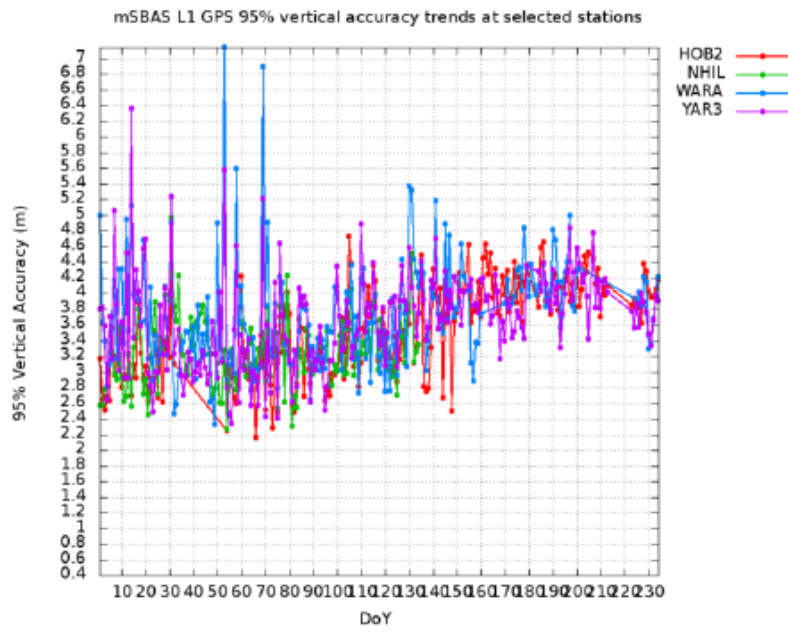

Figure 17 - Vertical P95 SF (SBAS)

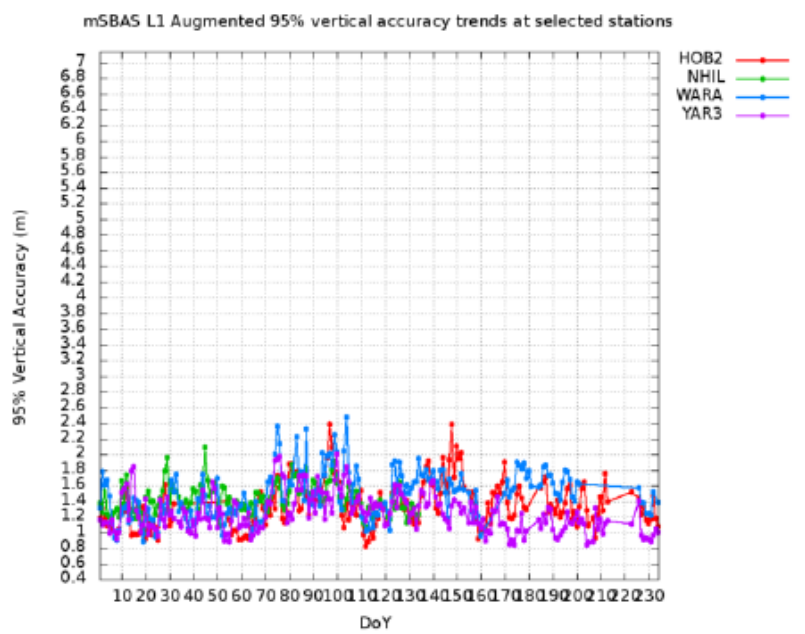




\subsection{SBAS L5 Performances}

The following plots show the accuracy results for WARA station through 2018. Red lines represent the GPS only results, while green lines represent the GPS+SBAS solution. Average and P95 are shown in the plot.

\section{Figure 18 - WARA Horizontal Accuracy DF}

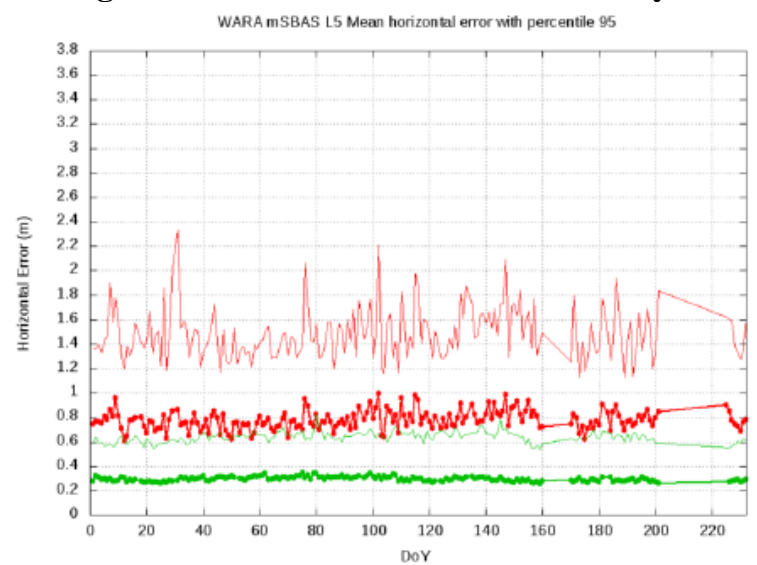

GPS onlymean $\rightarrow$ GPS-SBAS mean $\longrightarrow$ GPS only P95 —— GPS-SBAS P95

\section{Figure 19 - WARA Vertical Accuracy DF}

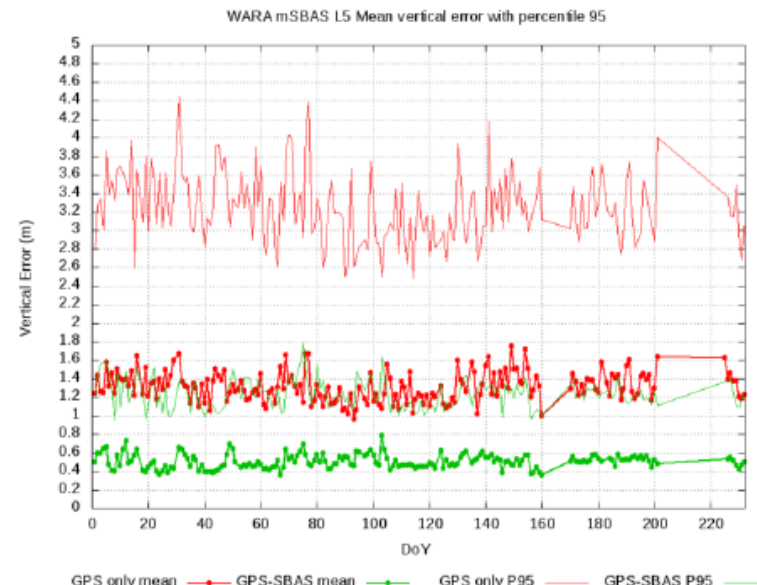

The figures show how the outcomes of L5 processing reproduces the behavior of SBAS L1 solutions. SBAS L5 DFMC augmentation systematically improves the accuracy of the solution. An interesting result of the plots is how the daily statistics for the SBAS DFMC solution are more stable than in the SBAS L1. This is assumed to be an effect of the removal of the ionosphere daily variability.

The following diagram shows the different clustering of the SBAS (green) and non SBAS (red) solution.
Figure 20 - WARA Daily Mean Errors DF

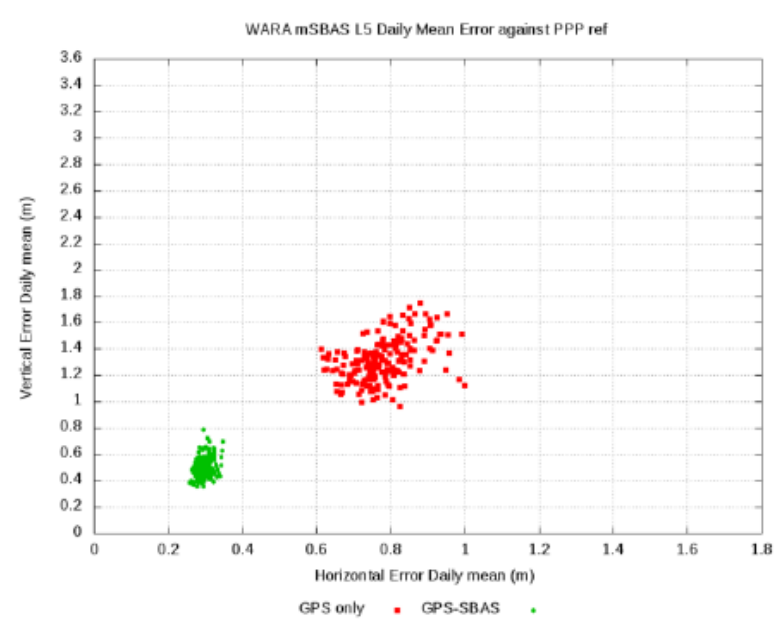

The following plot displays the vertical protection level average and P95 in comparison with the alert limits. The results indicate that the system solution is compatible with LPV-200 performances:

Figure 21 - WARA SBAS L5 Vertical PL

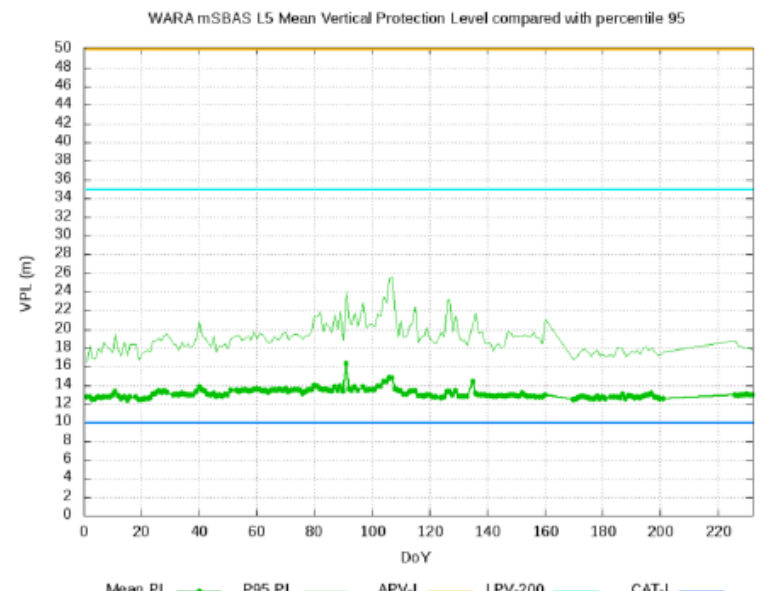

In this particular case, it is noted that the service is not matching CAT-I service (although this is the expected behavior when using only GPS constellation).

Once again, these outputs are comparable with the ones obtained in different reference stations. The following plots show the change on the P95 vertical accuracy from the GPS only solution to the GPS+SBAS solution. 
Figure 22 - Vertical P95 DF (non SBAS)

mSBAS L5 GPS $95 \%$ vertical accuracy trends at selected stations

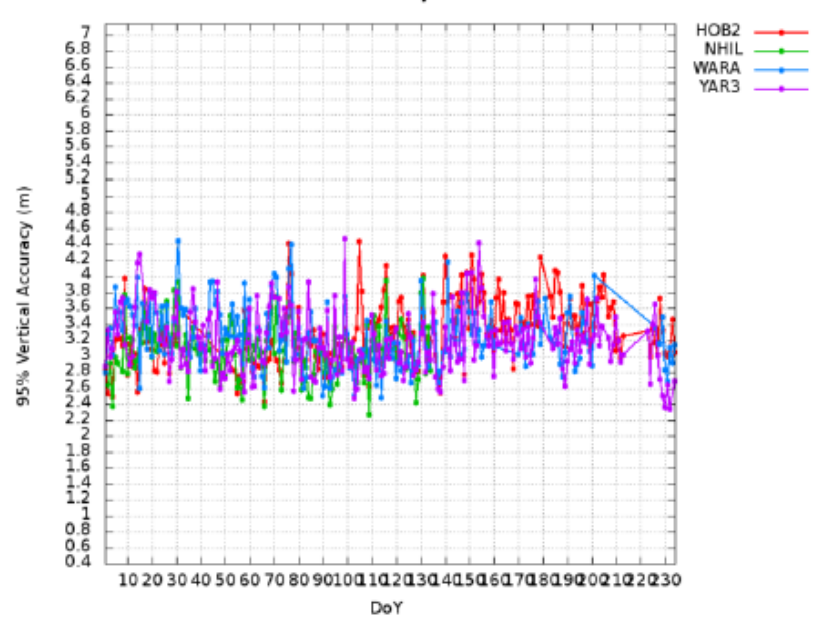

Figure 23 - Vertical P95 DF (SBAS)

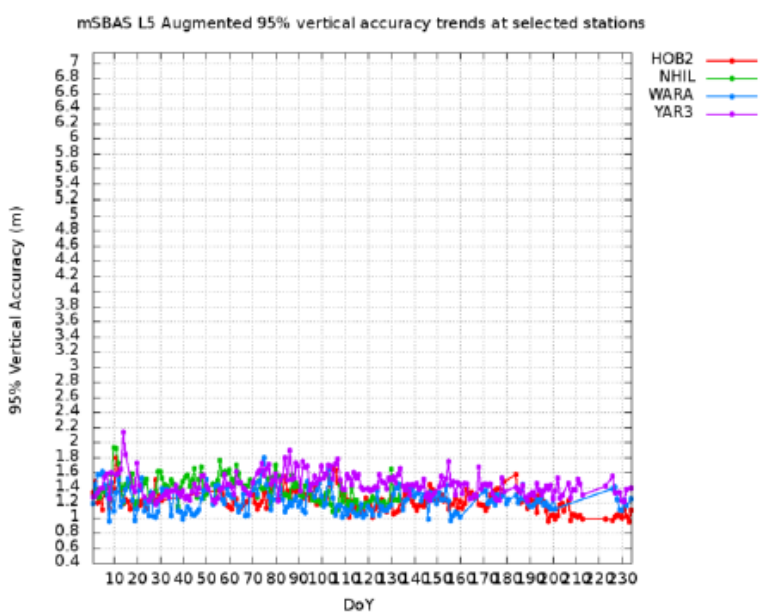

\section{SIS PERFORMACE ANALYSIS}

\subsection{Analysis Methodology}

Eclayr [8] implements the evaluation of the SBAS performances in terms of integrity, availability, accuracy and continuity considering only the characteristics of the SIS message. That is, removing the receiver local effect. This is achieved by comparing the information broadcast as part of the SBAS message with post-processed reference files describing the true behavior of the satellites and ionosphere (e.g IGS sp3 files and IONEX files).

In the context of the Australian and New Zealand testbed, the SBAS L1 and L5 messages tracked from LLRx (described in section 5) are analyzed with Eclayr. The following sections shows the results obtained.

\subsection{SBAS L1 SIS Analysis}

The following diagrams show the daily availability of the system for APV-I performances in SBAS L1 service from 03/06/2018 until 09/06/2018. Figures show the performance over a span of seven continuous days.
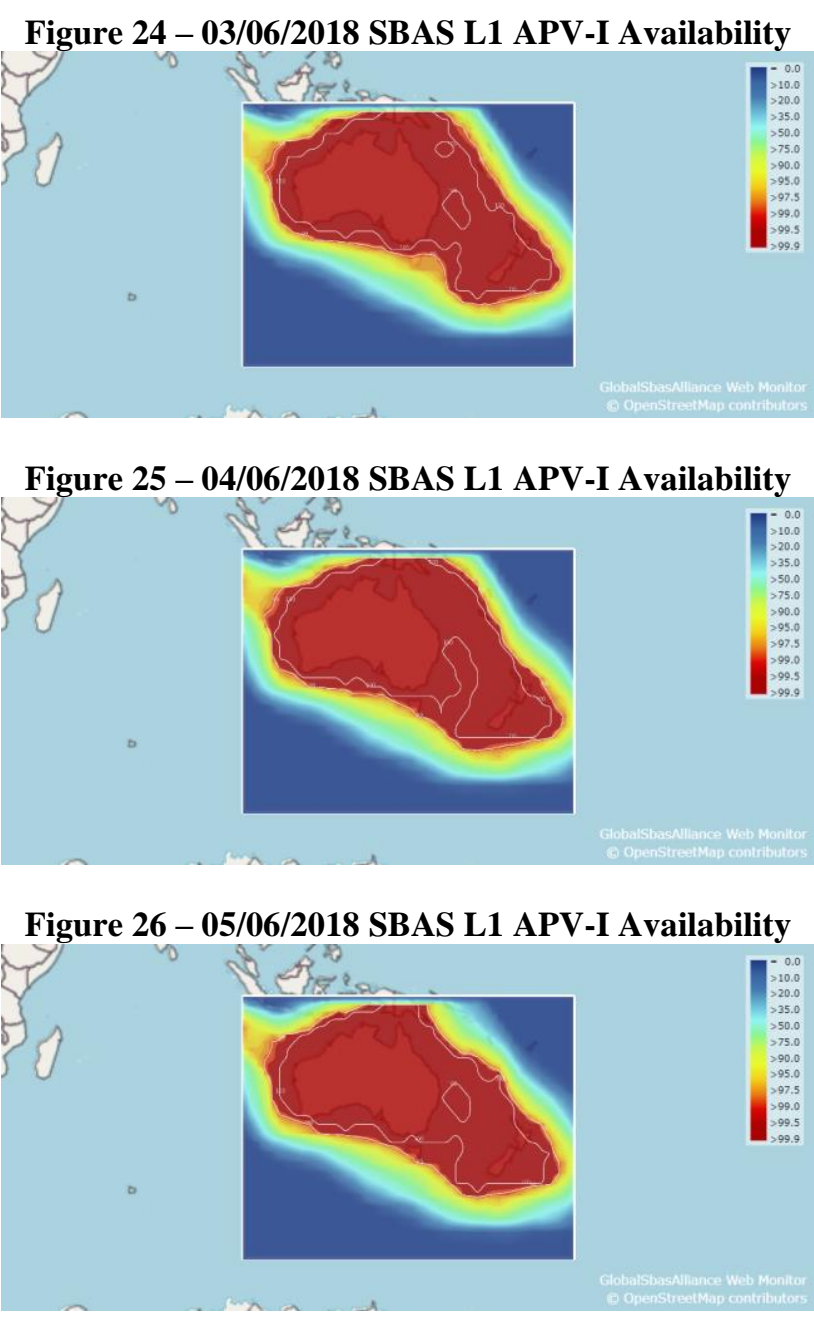

Figure 27 - 06/06/2018 SBAS L1 APV-I Availability

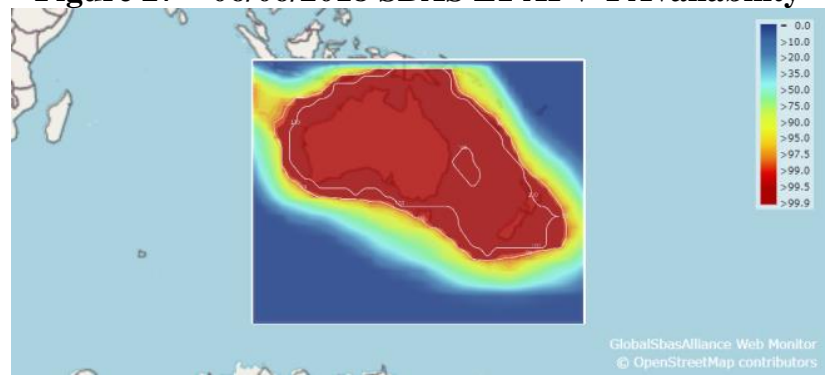

Figure 28 - 07/06/2018 SBAS L1 APV-I Availability

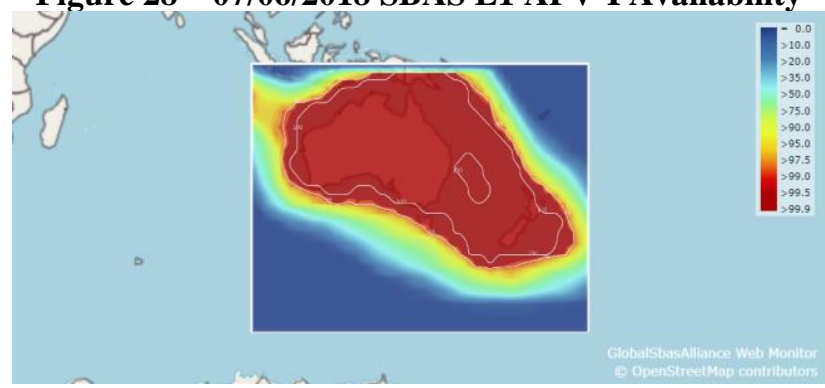



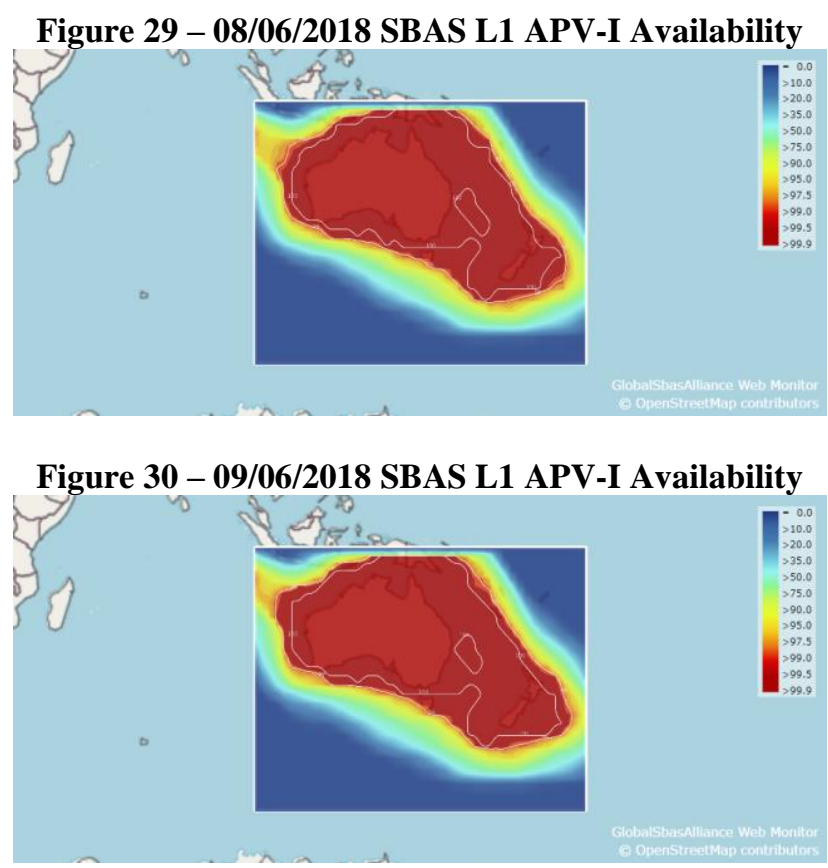

As it can be observed in the images, the $99.9 \%$ availability is reached for APV-I throughout the Australian continent and New Zealand Islands (including Chatham Island) with the majority of the Australian continental landings within the isoline of the $100 \%$. No integrity event is reported.

\subsection{SBAS L5 DFMC SIS Analysis}

The following sequence shows the equivalent analysis for the SBAS L5 DFMC when evaluated against LPV-200 protection levels. The SBAS DFMC L5 message performances is evaluated over entire Earth without checking the GEO visibility.

Figure 31 - 03/06/2018 SBAS L5 LPV-200 Availability

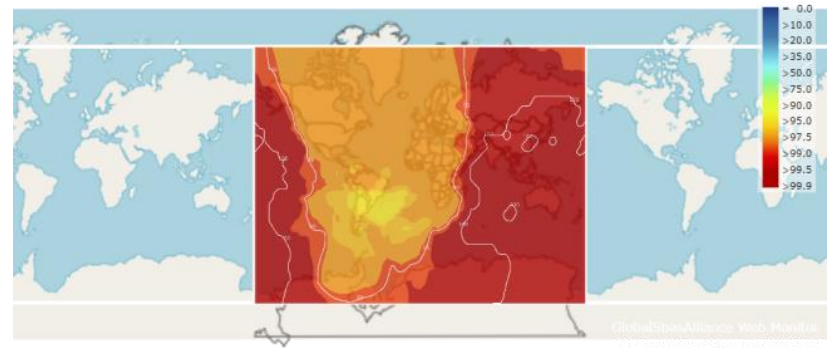

Figure 32 - 04/06/2018 SBAS L5 LPV-200 Availability

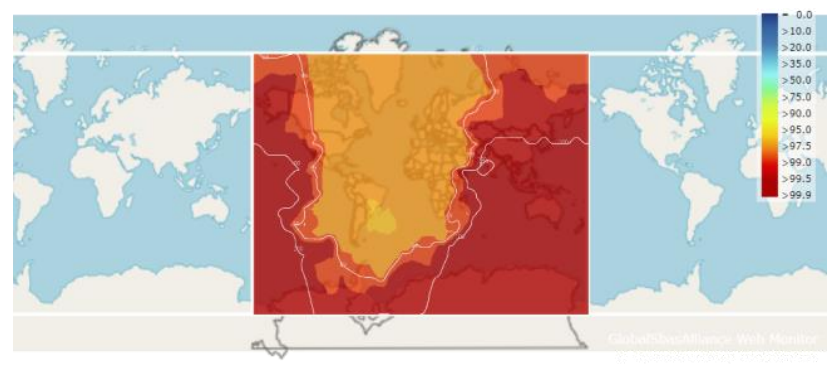

Figure 33 - 05/06/2018 SBAS L5 LPV-200 Availability

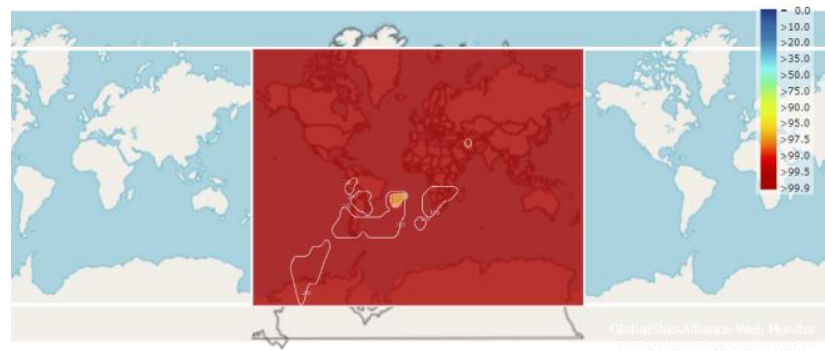

Figure 34 - 06/06/2018 SBAS L5 LPV-200 Availability

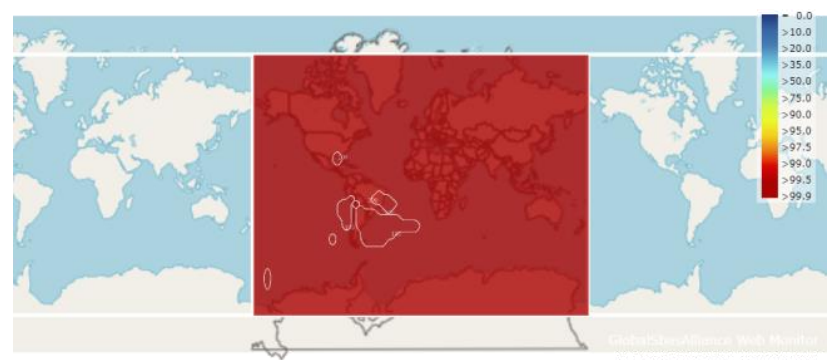

Figure 35 - 07/06/2018 SBAS L5 LPV-200 Availability

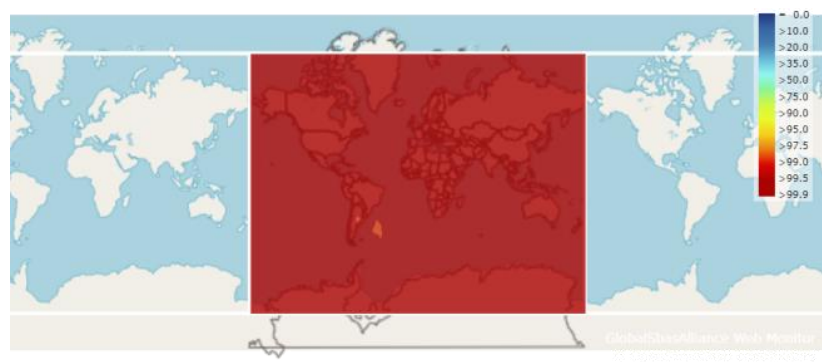

Figure 36 - 08/06/2018 SBAS L5 LPV-200 Availability

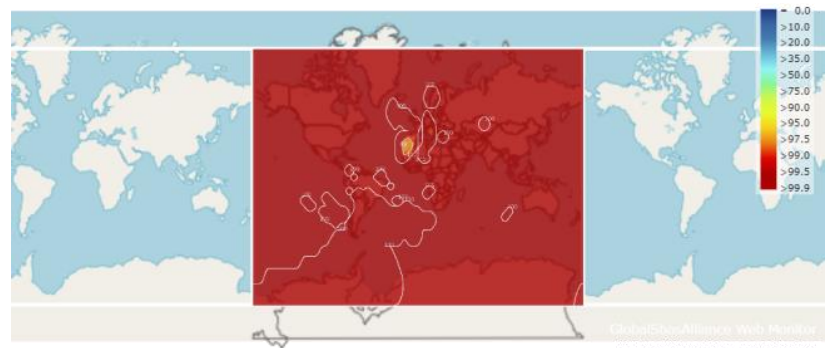

Figure 37 - 09/06/2018 SBAS L5 LPV-200 Availability

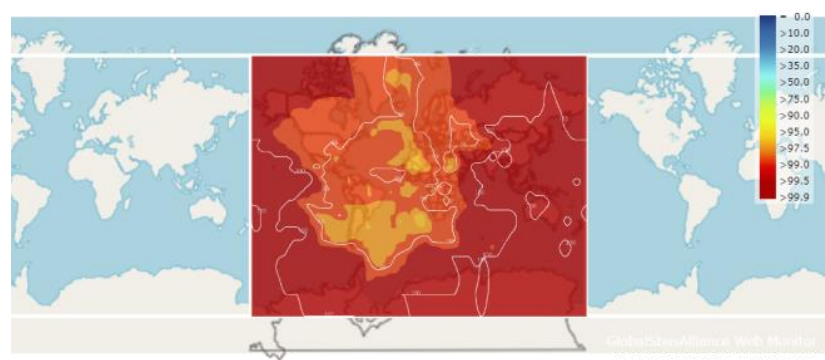

As is can be seen, the $100 \%$ availability is reach systematically for LPV-200 within the PRN 122 coverage Area. No integrity event is reported. It is noted that this result is achieved with an incomplete Galileo constellation. 
Interestingly it is observed how the LPV-200 availability is degraded (going down to $97.5 \%$ ) in the anti-pole of the GEO footprint (the Atlantic Area). This is an effect of the logic used in the design of the reference network.

One of the main constraints that the testbed has experienced is the reliability of the reception of the stations input data within the needed service latency. As the communication relays in general purpose protocols and internet communications, it is common to lose information from some receivers (or that information arrives late). As the integrity information must be based on $1 \mathrm{~Hz}$ information, the loss of data must clearly impact the service performances.

As shown in Figure 5, the SBAS L5 network is prioritizing the selection of stations in Australia. Since the communication infrastructure is located near the processing center at Uralla its data is more reliable in terms of latency. For the stations located in America, Africa and Europe the information must travel a longer path and their latency performances is worse.

This behavior is avoided in the design of a SBAS operational system where dedicated stations and communication means are available.

Within the testbed the redundancy in the Atlantic area stations has not been implemented partly because of limitations on the algorithms dimensioning and partly because of the no added value of improving the service in an area in which the GEO is not visible. Nevertheless the engineering team understands that the provision of testbed services is feasible world-wide with the adequate design of the reference network.

\section{TESTBED PPP PERFORMANCES}

\subsection{Analysis Methodology}

Within the Australia and New Zealand testbed, magicODTS is generating a stream of satellite precise orbit and clock corrections which is later codified within the SBAS message by magicSBAS. The original magicODTS corrections are also available in RTCM format for monitoring and analysis purposes.

The testbed team is systematically checking the performances of the PPP service by comparing the results achieved at a reference station (PARK) when it processes correction as received using by means of the RTCM protocol and the SBAS messages. Both corrections correspond to the same SV orbit and clock estimation but codified in different dissemination channels.

The processing of the data is performed in real-time by means of the magicAPK tool, which is receiving its input data with the NTRIP protocol in the case of the station data (observations and ephemeris) and RTCM corrections. In the case of the SBAS information, it is received by means of the SISNET protocol as transmitted from Processing Centre at Uralla.

The results are deemed fully representative of actual implementation through the GEO in terms of data International Technical Symposium on Navigation and Timing (ITSNT) 2018

13-16 Nov 2018

ENAC, Toulouse, France minutes). resolution an accuracy, update time-outs and message sequence.

A certain level of degradation is expected between the RTCM and PPP through SBAS results. This is mainly produced by a slightly loss resolution in the SBAS message, and the different update rates possible considering the GEO bandwidth. Nevertheless the result obtained prove the high consistency between RTCM and PPP results.

\subsection{PPP through SBAS L1}

The following plots shows the error RMS metric obtained when processing PARK station data with magicODTS precise corrections as transmitted through RTMC messages and SBAS L1 messages. Only GPS satellites are used:

\section{Figure 38 - 29/08/2018 GPS PPP (RTCM)}

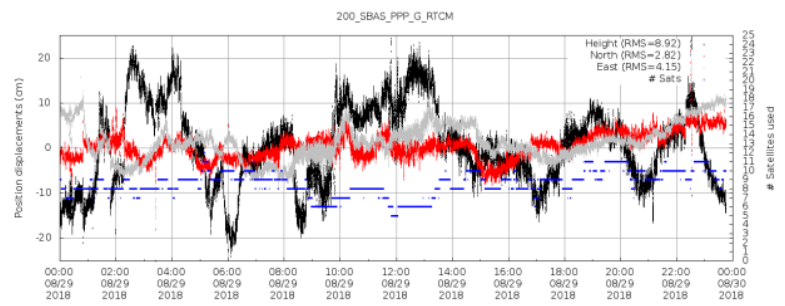

Figure 39 - 29/08/2018 GPS PPP (SBAS)

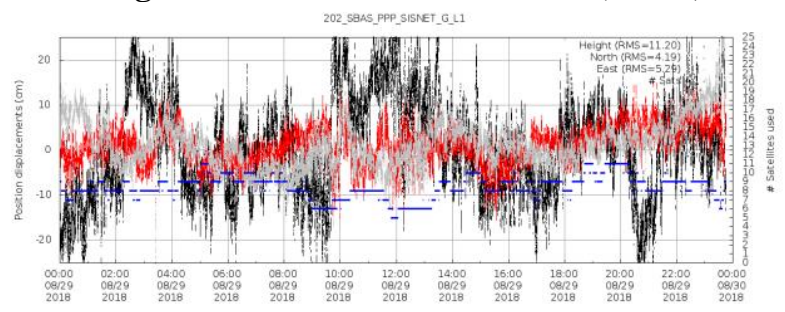

The two plots show a similar figure with the same evolution trends on the North, East and Up errors. However, the solution using the correction through the SBAS message presents more noise. This is a result of the higher updating rate of the information in the SBAS channel.

The daily tridimensional (3D) RMS error is $10.2 \mathrm{~cm}$ in the case of the RTMC source and $13.10 \mathrm{~cm}$ in the case of the SBAS source. A degradation of between 2 and $6 \mathrm{~cm}$ in the SBAS solution is expected with regards to the reference RTMC result.

The following diagrams show the evolution of the daily 3D RMS in RTCM and SBAS data during the analysis campaign (the data is filtered for convergence events appearing when the station data is lost for more than 15 
Figure 40 - Daily RMS with GPS (RTMC)

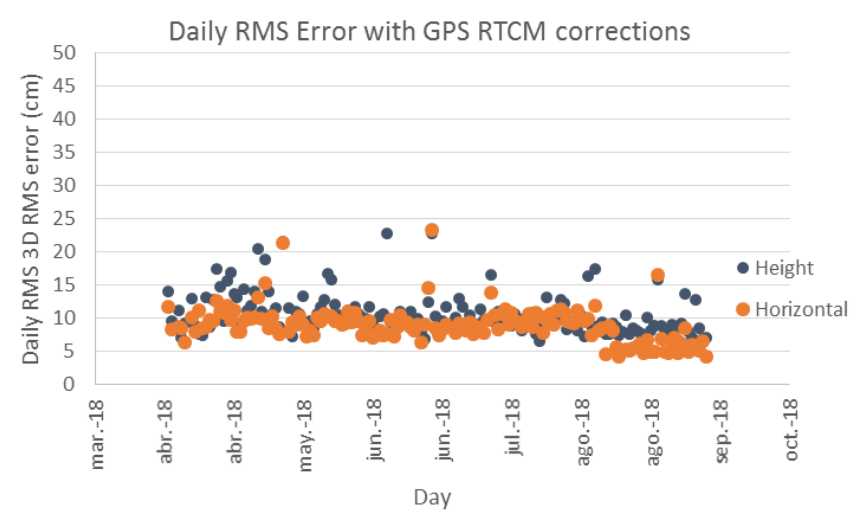

Figure 41 - Daily RMS with GPS (SBAS)

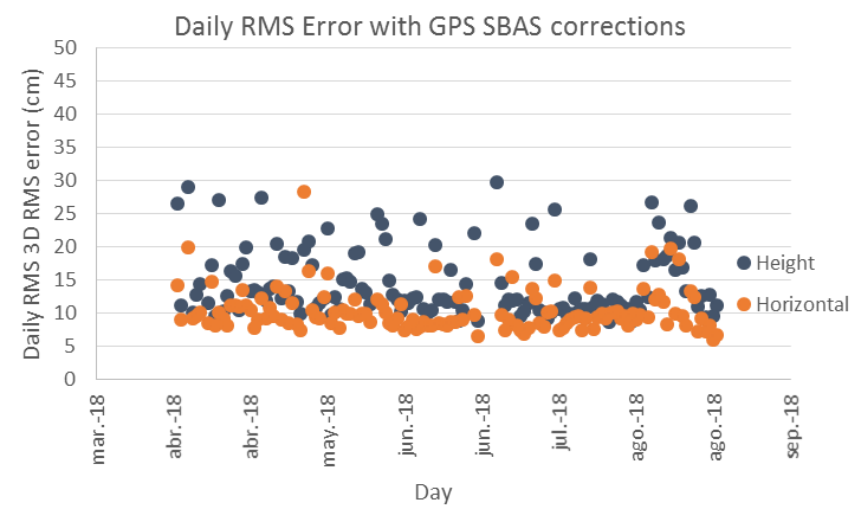

When considering only GPS satellites, the daily average horizontal RMS error is $8.97 \mathrm{~cm}$ in the case of the RTCM source and $10.17 \mathrm{~cm}$ in the case of the SBAS source. The daily average vertical RMS is $10.67 \mathrm{~cm}$ for RTCM source and $14.47 \mathrm{~cm}$ for SBAS L1 source. A degradation of between 2 and $5 \mathrm{~cm}$ in the SBAS solution is expected with regards to the reference RTCM result.

\subsection{PPP through SBAS L5}

The following plots show the error RMS metric obtained when processing PARK station data with magicODTS precise correction as transmitted through RTMC messages and SBAS L5 messages. Both GPS and Galileo satellites are used:

\section{Figure 42 - 29/08/2018 GPS+GAL PPP (RTCM)}

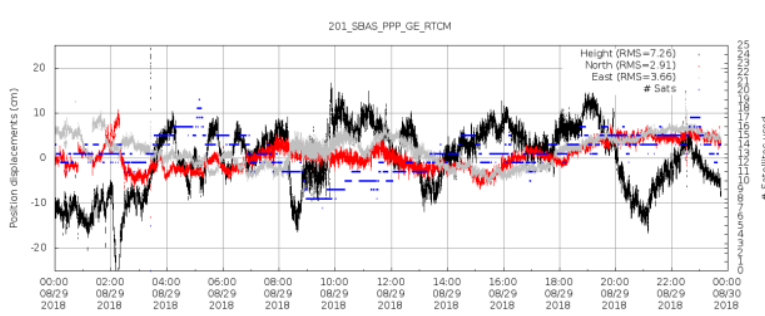

Figure 43 - 29/08/2018 GPS+GAL PPP (SBAS)

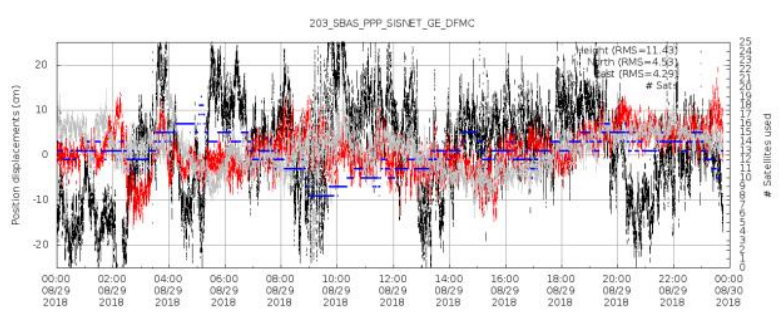

Similar to the L1 result, the SBAS solution error trends corresponds to the ones of the RTCM with an additional noise. The daily 3D RMS error is $8.63 \mathrm{~cm}$ in the case of the RTCM solution and $13.02 \mathrm{~cm}$ in the case of the SBAS solution.

The following diagrams show the evolution of the daily RMS in RTCM and SBAS data during the analysis campaign (as per L1, the data is filtered for convergence events).

Figure 44 - Daily RMS with GPS+GAL (RTMC)

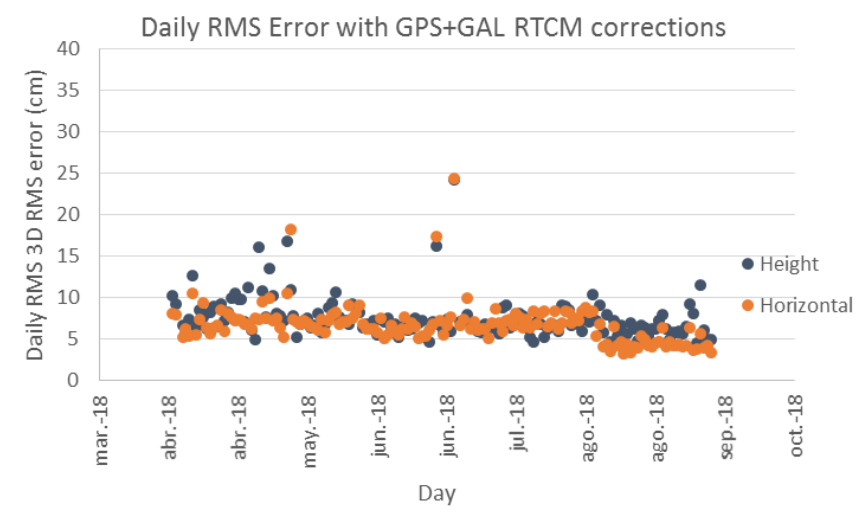

Figure 45 - Daily RMS with GPS+GAL (SBAS)

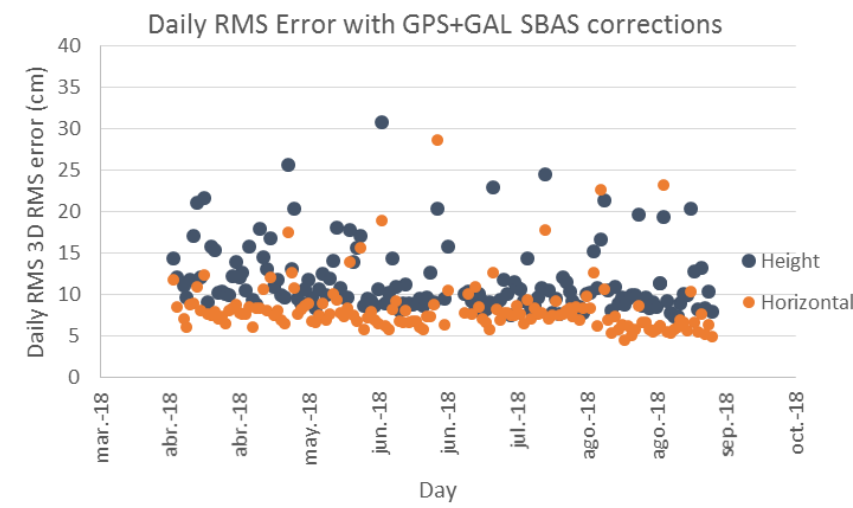

When considering GPS+GAL satellites, the daily average horizontal RMS error is $6.80 \mathrm{~cm}$ in the case of the RTCM source and $8.35 \mathrm{~cm}$ in the case of the SBAS source. The daily average vertical RMS is $7.54 \mathrm{~cm}$ for RTCM source and $11.69 \mathrm{~cm}$ for SBAS L1 source. It is also found that a degradation of between 2 and $5 \mathrm{~cm}$ in the SBAS solution is expected with regards to the reference RTCM result. 


\section{CONCLUSIONS}

The paper introduces the concept of a SBAS+PPP service and highlights the technical solutions upon which the Australia and New Zealand DFMC SBAS testbed is based, emphasizing the innovative aspects, such as the dissemination of SBAS L5 DFMC for the first time ever, the inclusion of PPP corrections in SBAS L1 and SBAS L5 messages, and the development of special user terminals for the demonstrations.

This paper also shows the preliminary performance achieved through the different services provided during 2018. The results obtained for both SBAS L1 and SBAS L5 are within the performance range expected for the system. First, the augmentation services are capable of improving the GPS navigation to a range of $50 \mathrm{~cm}$ average and $130 \mathrm{~cm}$ in $\mathrm{P} 95$ percentile. The use of the SBAS signal systematically improves the performances achieved with GPS only solutions. The protection levels achieved are compatible with the provision of a LPV-200 service over the Service Area. PPP service is proved to support consistently an accuracy service in better than 10 $\mathrm{cm}$ at horizontal RMS and $15 \mathrm{~cm}$ at $3 \mathrm{D}$ RMS.

\section{ACKNOWLEDGMENTS}

The authors wish to acknowledge the invaluable support given by the Australian and New Zealand authorities in the activities performed in the framework of the testbed, with special mention to Geoscience Australia, FrontierSI and Land Information New Zealand.

\section{DISCLAIMER}

The views and opinions expressed in this article are those of the authors and do not necessarily reflect the position of any institution of Australia or New Zealand.

\section{REFERENCES}

[1] RTCA, DO-229D Minimum Operational Performance Standards for Global Positioning System Airborne Equipment, 2006.

[2] Minimum Operational Performance Specification for Galileo / Global Positioning System /Satellite-Based Augmentation System Airborne Equipment; SBAS DFMC L5 MOPS Draft WG62_GAL_GPS_SBAS_MOPS_v0.3.8_10_Mar_2017.

[3] GMV, magicSBAS [Online] http://www.gmv.com/en/space/magicSBAS/index.html

[4] GMV, magicGNSS [Online]. Available: https://magicgnss.gmv.com/

[5] GMV, SR $\boldsymbol{X}-10$ [Online]

http://www.gmv.com/en/Products/srx-10/

[6] GMV, magicAPK [Online]

https://magicgnss.gmv.com/
[7] GMV, magicGEMINI [Online]

http://www.gmv.com/en/aeronautics/products/magicGEM INI

[8] GMV, Eclayr [Online]

https://www.gmv.com/en/Products/eclayr/ 